\title{
Peak and Average Power Handling Capability of Microstrip Filters
}

\author{
Miguel Á. Sánchez-Soriano, Member, IEEE, Yves Queré, Member, IEEE, Vincent Le Saux, \\ Stephan Marini, Member, IEEE, Marta Reglero, Vicente E. Boria Fellow, IEEE and \\ Cédric Quendo, Senior Member, IEEE
}

\begin{abstract}
In this work, the power handling capability of microstrip filters is studied in detail. This study is addressed from two perspectives, depending on the physical phenomenon limiting the maximum power that the microstrip filter can handle. One of these phenomena is air breakdown or corona effect, which is linked to the peak power handling capability (PPHC) of the device, and the other is the self-heating, which limits the device average power handling capability (APHC). The analysis is focused on three kinds of filtering topologies widely used both in academia and industry, such as the coupled-line, stepped impedance resonator and the dual-behaviour resonator based filters. Closed-form expressions are computed to predict both the PPHC and the APHC as a function of the geometrical parameters of the resonators integrating the filter. Guidelines are also given to extrapolate the provided computations to other filtering topologies based on other kinds of resonators. To validate this research study, three bandpass filters centered at $5 \mathbf{G H z}$ have been implemented and fully characterized by means of two measurements campaigns which have been carried out, one for the PPHC and another one for the APHC. The measured results have validated the performed study and corroborated the conclusions obtained throughout the paper.
\end{abstract}

Index Terms-Average power handling capability (APHC), coupled-line filter, electro-thermal analysis, microstrip filter, peak power handling capability (PPHC), power applications, stepped impedance resonator (SIR).

\section{INTRODUCTION}

$\mathbf{M}$ ICROSTRIP circuits have been widely used in the past, but also in the present, in a huge number of applications due to their low size and weight, low-cost manufacturing and easy integration with other devices. The flexibility of this technology allows the design of multitude of components, such as couplers, dividers and filters with very high demanding specifications, in terms of size as well as of transfer function response [1], [2]. In addition, microstrip technology also favors

Manuscript received xxx xx, 2018; revised xxx, yy. This work was supported by the "Agencia Estatal de Investigación (AEI)", under the coordinated research project TEC2016-75934-C4, by the University of Alicante under the research project GRE16-17 and by the Generalitat Valenciana under the research project GVA/2018/071.

Miguel Á. Sánchez-Soriano and Stephan Marini are with the Department of Physics, Systems Engineering and Signals Theory, University of Alicante, 03690 Alicante, Spain (e-mail: m.sanchez.soriano@iee.org)

Yves Queré and Cédric Quendo are with Lab-STICC, Université de Bretagne Occidentale, 6 avenue Le Gorgeu, 29238 Brest, France.

Vincent Le Saux is with ENSTA Bretagne, UMR CNRS 6027, IRDL, F29200 Brest, France

Marta Reglero is with the Val Space Consortium, Ciudad Politécnica de la Innovación, E-46022 Valencia, Spain.

Vicente E. Boria is with iTEAM, Universitat Politècnica de València, 46022 Valencia, Spain the design and development of multifunctional devices by integrating, in an easy way, varactors, diodes and/or microelectromechanical systems (MEMS) [3]-[5].

In any communication system, filters are a key part both in the transmitter and the receiver subsystems, to let pass the signals of interest, limit the bandwidth and related power of noise contributions, and reject the out-of-band or non-desired signals (which can come from the active stages of the transmitter and receiver, and/or be received by the antenna), thus keeping in this way a high dynamic range of the system. Microstrip bandpass filters BPFs have been widely studied and tackled in the literature, and one can find a large number of filtering topologies presenting a big variety of responses [6]; from the classical coupled-line and stepped impedance resonators filters, both to design narrow-to-moderate bandwidth BPFs, to other more recent filtering topologies for the design of wideband (or even ultra-wideband UWB) BPFs, such as signalinterference techniques [7]-[9] or multiple mode resonator (MMR) filters [10], [11]. Typically, microstrip filters are used in low power applications up to around $30 \mathrm{dBm}$. However, the rise and success of solid state power amplifiers (SSPAs) has put in the spotlight the use of microstrip filters also in the output stages of the high-power transmitters. This makes essential the study of the power handling capabilities of the most common used topologies implementing microstrip filters, especially for narrow-to-moderate bandwidth applications, where losses and voltage magnification can be important. In [12][14] the study of average power handling capability (APHC) of microstrip circuits has been addressed. The APHC is defined by the heat that the circuit is able to generate and how it is delivered to the environment. It has been shown that passive microstrip circuits presenting resonating elements may afford power levels up to $5 \mathrm{~W}$ keeping their maximum temperature lower than $100^{\circ} \mathrm{C}$, which avoids excessive thermal stress and any other damage in the circuit. However, the study of the peak power handling capability (PPHC), and its associated physical phenomenon, air ionization or corona effect, which has been widely studied for waveguide filters [15], [16], has hardly been reported in the literature for microstrip circuits, and if so, it has been just focused on the connector to microstrip line transition [17], [18]. However, as it will be shown in this paper, microstrip filters can present corona discharges at power levels much lower than those found for the coaxial-tomicrostrip transitions, which may turn them into the power limiting factor of the whole component.

The main aim of this paper is, therefore, to study in 
detail the average and peak power handling capabilities of typical microstrip filters, such as those based on coupled-line resonators and dual-behaviour resonators (DBRs), which are very well-known topologies and are widely used in multitude of applications. The paper is organized as follows: in Section II a theoretical analysis and modeling, regarding PPHC and APHC, of three very used microstrip filtering topologies is addressed. This modeling has been generalized in order to be extrapolated to other kinds of bandpass filtering configurations. In this regard, closed-form expressions have been obtained for the estimation and prediction of the maximum power (both average and peak power) that a microstrip filter can afford as a function of the characteristics of filter resonators. Several examples are analyzed and the analytically computed values are compared to simulations showing a very good agreement. Section III describes the two measurements campaigns which have been carried out to validate this research study (one for the PPHC study and the other for the APHC one). Three bandpass filters operating in the band of $5 \mathrm{GHz}$ have been implemented and fully characterized in the performed experimental campaigns. The measurements results have validated and corroborated the performed study. In Section IV, the limitations of the theoretical predictions are discussed, and finally, Section V summarizes the main conclusions of this work.

\section{Description, Theoretical Analysis And MODELING OF MICROSTRIP FILTERS}

For the design of bandpass filters in microstrip technology with narrow-to-moderate bandwidth, filters based on coupledlines and stubs (and their variations) are probably the most well-known and chosen topologies. They have been widely used in a successful way both in scientific and commercial contexts. With these topologies it is possible to design bandpass filters in the range of $1-20 \%$ with a moderate size. Narrower bandwidths would still be possible but at the expense of excessive insertion loss for most of applications, unless ultra-low loss materials, such as superconductors above ceramic substrates, were used. Fig. 1 shows the layout of three very common kinds of these filters: one of them based on half-wavelength parallel-coupled line resonators and the remaining two based on stub-based dual-behaviour resonators DBRs [19], [20]; for the latter ones the difference between them is the termination of the stub resonators (either open- or shor-circuited). The power handling capability study is going to be focused on these third order filters, while it can be easily extended to other similar topologies.

The power handling capability study is addressed in two different ways, depending on the kind of the input signal, either continuous wave $\mathrm{CW}$ or pulsed, which will lead to different physical phenomena occurring in the device. For CW input signals, the power limitation, called average power handling capability (APHC), is defined by thermo-mechanical effects which can happen in the structure due to the selfheating produced in the device. For pulsed signals, the power limit, named in this case, peak power handling capability (PPHC), will be probably produced by the air ionization, i.e., due to a corona phenomenon.

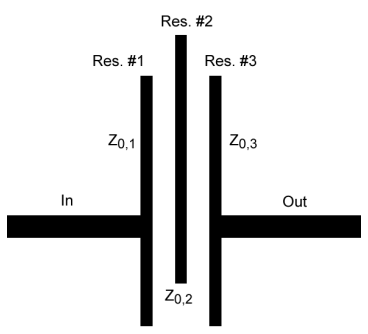

(a)

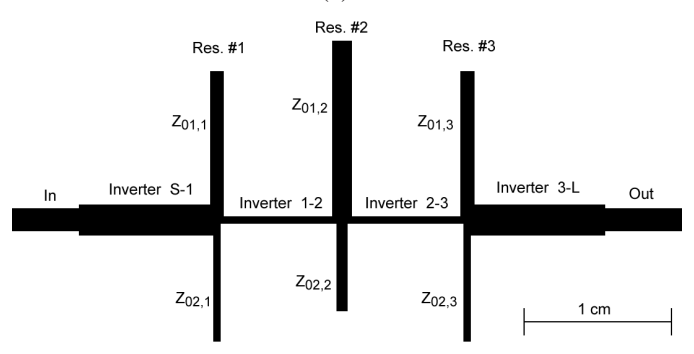

(b)

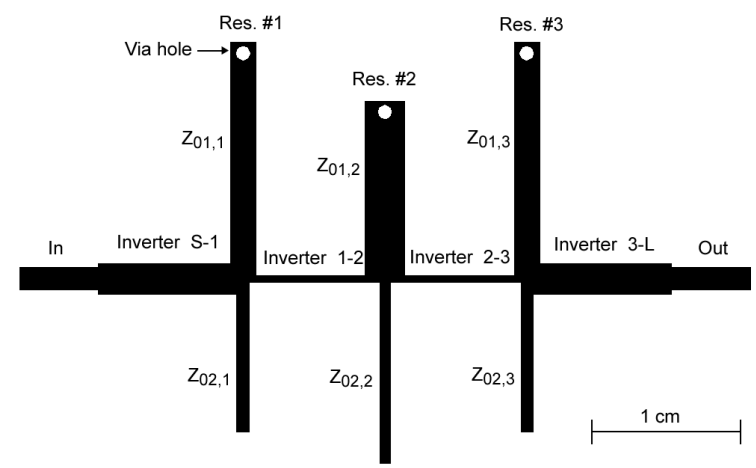

(c)

Fig. 1. Layout of the three kinds of filters under study. (a) $\lambda / 2$ coupled-line filter. (b) Filter based on DBRs type I. (c) Filter based on DBRs type II. All filters are designed on the same substrate $\left(\epsilon_{r}=3.75\right.$, thickness $h=0.711$ $\mathrm{mm}$ and loss tangent $\tan \delta=0.007$ ) to be centered at $5 \mathrm{GHz}$ and have a fractional bandwidth of $\mathrm{FBW}=5 \%$. More details about them will be given in the following sections. Layouts plotted at the same scale.

\section{A. Peak Power Handling Capability}

For pulsed signals with a low duty cycle DT (let us say, DT $<2 \%$ ), the effective or average power applied to the microstrip filter $\left(P_{i n, a v}=P_{i n} \cdot \mathrm{DT}\right.$, where $P_{i n}$ is the carrier input signal power ${ }^{1}$ ) is considerably reduced with respect to the carrier input signal power (by a factor higher than 50, following the previous range of DT). Since the heat produced in the device is directly proportional to the effective input power, low DT values will lead to consider the selfheating in the device to be practically negligible. Under this scenario, and taking into account that the dielectric substrates commonly used in microwave applications present very high limits of dielectric breakdown, mainly in comparison to the

\footnotetext{
${ }^{1}$ Please note that for communication signals, such as OFDM ones, $P_{i n}$ in some intervals could be $10 \mathrm{~dB}$ higher (or even more) than the power linked to a subcarrier signal [15].
} 
air ionization limits, a corona discharge will probably limit the power handling capability of the filter. In this regard, the power ranges and environmental conditions where a big self-heating and a corona discharge may co-exist will also be discussed at the end of this paper.

The corona phenomenon is directly linked to the air ionization produced by a strong electric field. Thus, the maximum electric fields in the air of the filters must be computed. For this purpose, firstly the voltage and current of each resonator $i$ of the equivalent lumped element filter are obtained as

$$
\begin{gathered}
v_{i}=\frac{v_{g}}{q_{e}}[A]_{i, 1}^{-1} \\
i_{i}=\frac{v_{g}}{q_{e} R}[A]_{i, 1}^{-1}
\end{gathered}
$$

where $v_{g}$ is the generator voltage, $q_{e}$ the normalized external quality factor, $R$ is the reference impedance and $[A]$ is the normalized impedance/admittance matrix defining the filter network [6]. Once the equivalent voltages/currents are known, the following step is to calculate the stored energy per resonator as

$$
W_{i}=\frac{4 P_{i n}}{q_{e} \mathrm{BW}}[A]_{i, 1}^{-2}
$$

where BW is the absolute bandwidth of the filter in $\mathrm{rad} / \mathrm{s}$. At resonance, the stored energy by every resonator of the equivalent lumped element network should be the same as that associated to the distributed resonators forming the filter [15], [21], [22]. Therefore, the kind of resonator used will play an important role and, depending on its geometry, different levels of PPHC could be reached.

The energy stored by each distributed resonator $W_{\text {distr }}$ can be computed from its voltage and current standing waves by integrating them along the resonator length, as in [23], [24] (see Appendix A). The standing waves for each kind of resonator, which have form of sinusoidal functions, are found from its boundary conditions, and additionally, for the case of step impedance resonators, also from the continuity conditions in the step impedance planes. Indeed, the boundary conditions along with the continuity conditions give the selfresonance frequency of each kind of resonator. Fig. 2 shows the voltage and current standing waves for the different resonators involved in the filter topologies under study (the case for the $\lambda / 4$ resonator is also shown due to its popularity, although it has not been used in the filter topologies under study). As seen from this figure, the maximum voltage $V_{\text {peak }}$ for each kind of resonator is happening at the open-circuit terminations, as expected. It should be noted that for the case of step impedance resonators (or dual-behaviour resonators), two different $V_{\text {peak }}$ are found, each one in each section of the resonator. The maximum value of them will be defined by the characteristic impedance and electrical length of each line section, i.e. $Z_{01}, Z_{02}, \theta_{1}$ and $\theta_{2}$, although normally $V_{\text {peak }}$ will be placed at the termination of the line section presenting a higher characteristic impedance. Thus, by knowing the standing waves at resonance of each kind of resonators and

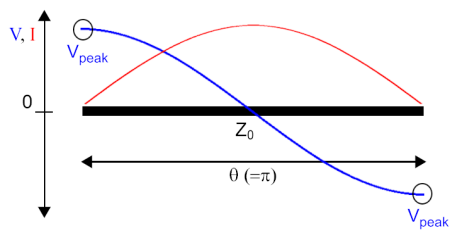

(a)

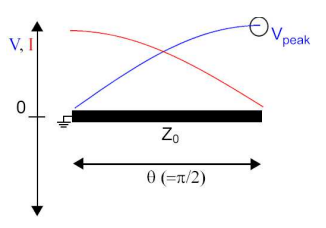

(b)

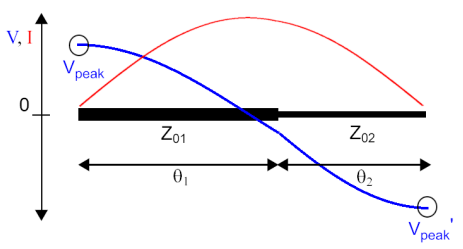

(c)

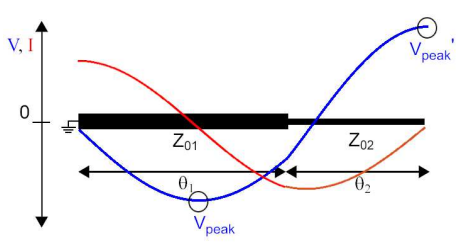

(d)

Fig. 2. Voltage and current standing waves at resonance for different kind of resonators. (a) Open-ended $\lambda / 2$ resonator. (b) $\lambda / 4$ resonator. (c) Dualbehaviour resonator type I. d) Dual-behaviour resonator type II.

making $W_{i}=W_{\text {distr, } i}$, the peak voltage of the resonator $i$ $\left(V_{\text {peak,i }}\right)$ in a bandpass filter can be analytically obtained as

$$
V_{\text {peak }, i}=4 \sqrt{\frac{P_{\text {in }}}{q_{e} \cdot \mathrm{FBW} \cdot \chi_{i}}}[A]_{i, 1}^{-1}
$$

where FBW is the filter fractional bandwidth and $\chi_{i}$ is a parameter which depends on the kind of resonator involved in the filter topology. Table I shows the value of $\chi$ as a function of the characteristic impedances and electrical lengths defining each kind of resonator. According to (4), two microstrip BPFs with identical synthesis filtering response may present different PPHC depending on the value of $\chi$. This makes $\chi$ a new design parameter which could be taken into account in the design procedure of a microstrip BPF. $\chi$ should be maximized in order to reduce $V_{\text {peak }}$ leading to an increase of PPHC of the filter.

Table II gives the design parameters of the three filters under study of Fig. 1 along with the associated $\chi$ for each resonator. The design specifications for all filters are: $0.01 \mathrm{~dB}$ ripple Chebyshev response with $f_{0}=5 \mathrm{GHz}$ and $\mathrm{FBW}=5 \%$. Since all filters are designed to present the same electric filtering response and the unloaded quality factor $Q_{u}$ for all involved resonators is nearly equal, one can expect that the DBR type II filter is going to present the highest PPHC due to its higher $\chi$, whereas the filter based on DBR type I the lowest. This will be confirmed next both in simulations and measurements.

Fig. 3 shows the computed peak voltage in each resonator as a function of frequency for a 3rd order Chebyshev-type BPF centered at $5 \mathrm{GHz}$ and based on $\lambda / 2$ coupled-line resonators. The maximum $V_{\text {peak }}$ is found for the resonator \#1 and near the cut-off frequencies, as expected. One parameter which is 
TABLE I

$\chi$ FUNCTION FOR EACH KIND OF RESONATOR

\begin{tabular}{|c|c|}
\hline Kind of resonator & $\chi$ function \\
\hline$\lambda / 2$ & $\frac{\pi}{Z_{0, i}}$ \\
\hline$\lambda / 4$ & $\frac{\pi}{2 Z_{0, i}}$ \\
\hline DBR type I & $\begin{array}{l}\text { For } V_{\text {peak }}: \frac{1}{Z_{01, i}}\left(\theta_{1, i}+\frac{1}{2} \sin 2 \theta_{1, i}\right)+\frac{1}{Z_{02, i}}\left(\frac{\cos \theta_{1, i}}{\cos \theta_{2, i}}\right)^{2} \cdot\left(\theta_{2, i}+\frac{1}{2} \sin 2 \theta_{2, i}\right) \\
\text { For } V_{\text {peak }}^{\prime}: \frac{1}{Z_{01, i}}\left(\frac{\cos \theta_{2, i}}{\cos \theta_{1, i}}\right)^{2} \cdot\left(\theta_{1, i}+\frac{1}{2} \sin 2 \theta_{1, i}\right)+\frac{1}{Z_{02, i}}\left(\theta_{2, i}+\frac{1}{2} \sin 2 \theta_{2, i}\right)\end{array}$ \\
\hline DBR type II & $\begin{array}{l}\text { For } V_{\text {peak }}: \frac{1}{Z_{01, i}}\left(\theta_{1, i}-\frac{1}{2} \sin 2 \theta_{1, i}\right)+\frac{1}{Z_{02, i}}\left(\frac{\sin \theta_{1, i}}{\cos \theta_{2, i}}\right)^{2} \cdot\left(\theta_{2, i}+\frac{1}{2} \sin 2 \theta_{2, i}\right) \\
\text { For } V_{\text {peak }}^{\prime}: \frac{1}{Z_{01, i}}\left(\frac{\cos \theta_{2, i}}{\sin \theta_{1, i}}\right)^{2} \cdot\left(\theta_{1, i}-\frac{1}{2} \sin 2 \theta_{1, i}\right)+\frac{1}{Z_{02, i}}\left(\theta_{2, i}+\frac{1}{2} \sin 2 \theta_{2, i}\right)\end{array}$ \\
\hline
\end{tabular}

For the DBR type I and II, the two functions of $\chi$ correspond to the two possible values of $V_{\text {peak }}$, as Fig. 2 shows.

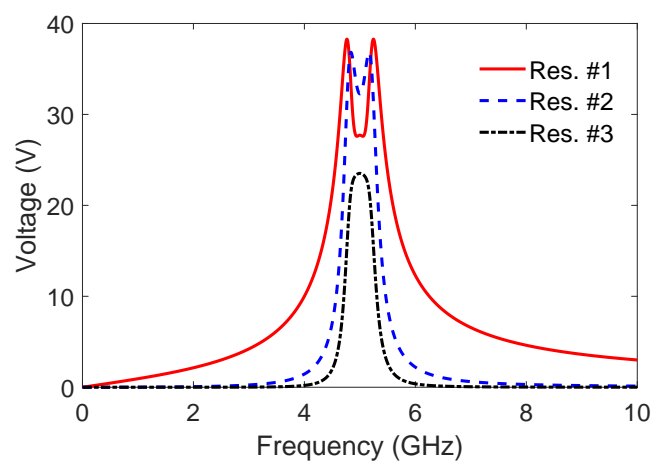

Fig. 3. $V_{\text {peak }}$ per resonator for a 3rd order Chebyshev-type BPF centered at $5 \mathrm{GHz}$ based on $\lambda / 2$ coupled-line resonators. Other parameters: Unloaded quality factor of each resonator $Q_{u}=110, \mathrm{FBW}=5 \%$ and $P_{i n}=1 \mathrm{~W}$.

important in order to pre-evaluate how a filter can be sensitive to a corona discharge is the voltage magnification factor VMF. $\mathrm{VMF}$ is defined as $V_{\text {peak }} / V_{0}, V_{0}$ being the voltage for a matched line $V_{0}=\sqrt{P_{\text {in }} \times 2 Z_{0}}$. So, VMF can be expressed for a filter as

$$
\mathrm{VMF}_{i}=4 \sqrt{\frac{1}{2 q_{e} \cdot \mathrm{FBW} \cdot \bar{\chi}_{i}}}[A]_{i, 1}^{-1}
$$

where $\overline{\chi_{i}}=\chi_{i} \cdot Z_{0}$. For the example of Fig. 3, the maximum voltage magnification is 3.8 . This means that this filter would have a PPHC around 14 times lower than that of a matched line. For each device under study, two characteristic frequencies are to be analyzed: the frequency where voltage magnification is maximum and the center frequency.

The air ionization is a phenomenon linked to the electric field strength rather than to the voltage. So, the maximum electric field strength should be computed for each resonator. The electric field lines can be considered to be uniformly
TABLE II

DESIGN PARAMETERS OF THE THREE FILTERS UNDER STUDY

\begin{tabular}{c|c|c|c}
\hline \hline Filter topology & Resonator & $Z_{0(1,2)}$ and $\theta_{(1,2)}$ & $\chi$ \\
\hline \hline Coupled-line filter & All res. & $70, \pi$ & 0.045 \\
\hline \multirow{2}{*}{ DBR type I filter } & Res. \#1 \& \#3 & 68,93 and $0.59 \pi, 0.43 \pi$ & 0.030 \\
& Res. \#2 & 55,76 and $0.71 \pi, 0.33 \pi$ & 0.040 \\
\hline \multirow{2}{*}{ DBR type II filter } & Res. \#1 \& \#3 & 46,71 and $0.87 \pi, 0.59 \pi$ & 0.054 \\
& Res. \#2 & 34,74 and $0.67 \pi, 0.71 \pi$ & 0.062 \\
\hline
\end{tabular}

The extracted $Q_{u}$ values (from full-wave simulations) for all involved resonators are in the range 90 to 110 .

distributed just below the strip conductor, as shown in Fig. 4. This first order approximation works reasonably well for not very narrow strips. Under this assumption, the electric field strength can be computed in the dielectric as

$$
\left|E_{\text {peak }, i}\right|=\frac{V_{\text {peak }, i}}{h}
$$

where $h$ is the substrate thickness. In the interface between air and dielectric, the following boundary conditions are fulfilled:

$$
\begin{aligned}
& \vec{n} \cdot \vec{D}_{\text {air }}=\vec{n} \cdot \vec{D}_{\text {diel }} \rightarrow E_{\text {air }, n}=\epsilon_{r} \cdot E_{\text {diel }, n} \\
& \nabla \times \vec{E}_{\text {air }}=\nabla \times \vec{E}_{\text {diel }} \rightarrow E_{\text {air }, \text { tan }}=E_{\text {diel }, \text { tan }}
\end{aligned}
$$

where $\vec{D}$ is the electric flux density and the subscripts $n$ and tan denote normal and tangential components of electric field, respectively. So, according to (7a) the normal electric field is magnified by a factor $\epsilon_{r}$ just in the corners of the microstrip line. Thus, as a maximum limit, this means that $\left|E_{p e a k, i}\right|$ computed in (6) should be multiplied by $\epsilon_{r}$ in order to obtain the maximum electric field strength in each resonator.

For a high pressure regime (i.e., pressures higher than 100 mbar), the air ionization breakdown threshold (peak value) can be determined by following the rule [25]

$$
\left|E_{\text {break }}\right|=42.7 \sqrt{p^{2}+2 f^{2}}(\mathrm{~V} / \mathrm{cm})
$$




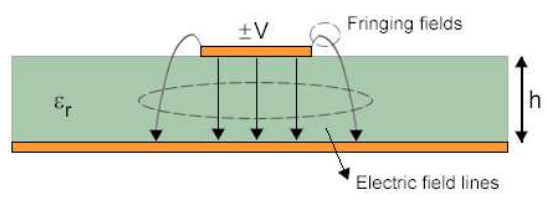

Fig. 4. Cross-section of a microstrip line where the electric field lines are shown. Please note that the figure is for the case where the main conductor has a voltage of $+V$. If it were $-V$ the electric field lines would have just the opposite direction.

TABLE III

MAXIMUM INPUT POWER THRESHOLD (IN WATTS). COUPLED-LINE FILTER.

\begin{tabular}{c|cc|cc}
\hline \hline \multirow{2}{*}{ Pressure (mbar) } & \multicolumn{2}{|c|}{ Simulated } & (SPARK 3D) & \multicolumn{2}{|c}{ Theoretically computed } \\
\cline { 2 - 5 } & $5 \mathrm{GHz}$ & $5.2 \mathrm{GHz}$ & $5 \mathrm{GHz}$ & $5.2 \mathrm{GHz}$ \\
\hline \hline 600 & 140 & 76 & 92 & 66 \\
\hline 800 & 201 & 110 & 163 & 116 \\
\hline 1013 & 268 & 147 & 262 & 187 \\
\hline
\end{tabular}

where $p$ is the pressure in torr and $f$ is the operation frequency in GHz. Therefore, at this point, by combining (4), (6), (7a) and (8), PPHC can be analytically computed for any kind of filter based on the resonators previously discussed for high pressures. For low pressure regime, the continuity equation describing the electron density evolution must be solved. This arduous task must be done numerically. In this work the software tool SPARK3D ${ }^{\circledR}$ (Aurora Software and Testing SL, v. 2014) is employed. This tool uses the real electromagnetic field distribution of the device under test (coming from a full wave simulator) in order to solve the continuity equation, and provides the power breakdown threshold of the device from some input parameters such as pressure, kind of gas (air or nitrogen) and temperature.

As an example of validation of the developed model, for the implemented 3rd order coupled-line filter of Fig. 1(a), the analytically computed maximum power threshold for $p=800$ mbar and $f=5.2 \mathrm{GHz}$ (frequency where VMF is maximum) has been of $116 \mathrm{~W}$ whereas the computed one with SPARK3D has been of $110 \mathrm{~W}$. In general, for the three implemented filters of Fig. 1, the difference between the analytically computed maximum power thresholds and the computed ones with SPARK3D in the pressure range [6001013] mbar has been always lower than $35 \%$ for the two characteristic frequencies, i.e., 5.2 (or 4.8 ) $\mathrm{GHz}$ and $5 \mathrm{GHz}$, with an average difference between simulated and analytically computed values of $19 \%$ (see Tables III-V). It means an average difference lower than $1 \mathrm{~dB}$.

It is worth mentioning that if the maximum electric field strength of the device under test DUT is simply taken from an electromagnetic tool (note that a normalization could be needed depending on the software) and then, the rule (8) is applied - which is, indeed, a common strategy used in industry-, a very conservative value for PPHC will be probably found (around one order of magnitude lower than those analytically predicted here or found with SPARK3D). This is
TABLE IV

MAXIMUM INPUT POWER THRESHOLD (IN WATTS). DBR TYPE I FILTER.

\begin{tabular}{c|cc|cc}
\hline \hline \multirow{2}{*}{ Pressure (mbar) } & \multicolumn{2}{|c|}{ Simulated (SPARK 3D) } & \multicolumn{2}{|c}{ Theoretically computed } \\
\cline { 2 - 5 } & $5 \mathrm{GHz}$ & $5.2 \mathrm{GHz}$ & $5 \mathrm{GHz}$ & $5.2 \mathrm{GHz}$ \\
\hline \hline 600 & 73 & 67 & 69 & 44 \\
\hline 800 & 104 & 96 & 122 & 78 \\
\hline 1013 & 145 & 127 & 195 & 125 \\
\hline
\end{tabular}

TABLE V

MAXIMUM INPUT POWER THRESHOLD (IN WATTS). DBR TYPE II FILTER

\begin{tabular}{c|cc|cc}
\hline \hline \multirow{2}{*}{ Pressure (mbar) } & \multicolumn{2}{|c|}{ Simulated (SPARK 3D) } & \multicolumn{2}{|c}{ Theoretically computed } \\
\cline { 2 - 5 } & $5 \mathrm{GHz}$ & $5.2 \mathrm{GHz}$ & $5 \mathrm{GHz}$ & $5.2 \mathrm{GHz}$ \\
\hline \hline 600 & 281 & 68 & 182 & 67 \\
\hline 800 & 410 & 94 & 323 & 119 \\
\hline 1013 & 590 & 142 & 519 & 191 \\
\hline
\end{tabular}

because the maximum electric field strength found from EM simulations may just happen over distances of a few microns, which is not enough to alter the electron density of the device. Another source of error of the strategy just mentioned in this paragraph is the employed mesh in the simulations, which could lead to some singularities in the computation of the electric fields.

\section{B. Average Power Handling Capability}

For such applications in which the effective applied input power to the circuit $P_{i n, a v}$ is higher than several hundreds of milliwatts, the self-heating in microwave planar devices can be noticeable and limit the PHC. For the study of the APHC, a multiphysics approach must be tackled, where the electro-thermo-mechanical coupling in the circuits under study is analyzed. In any passive microstrip circuit, there appear three loss mechanisms: ohmic, dielectric and radiation losses. The two former loss mechanisms are linearly proportional to the input power and generate heat in the circuit, i.e., they are the internal heat sources in the structure, whereas the latter does not generate any heat in the circuit and is, therefore, neglected in this electro-thermal study.

The heat generation in the circuit can be even more important as the operation frequency increases and the circuit area is reduced, which is actually the general trend in communication systems.

To compute the maximum temperature under $\mathrm{CW}$ of the filters under study, a procedure similar to that proposed in [14] is followed, here particularized for filters. It can be summarized in the following steps:

1) Compute the insertion loss and the return loss of the filter at the frequency of interest, in order to compute the heat generated in the whole circuit. The heat generated per watt $\Gamma$ is, therefore, calculated as

$$
\begin{aligned}
& \Gamma=\Gamma_{\text {total }}-P_{\text {rad }}= \\
& 1-1 / \mathrm{IL} \text { (linear) }-1 / \mathrm{RL} \text { (linear) }-P_{\text {rad }},
\end{aligned}
$$

where $\Gamma_{\text {total }}$ refers to the total loss factor in the device (accounting for all loss mechanisms), IL and RL denote 
insertion loss and return loss of the whole circuit, respectively, and $P_{\text {rad }}$ denotes the radiation loss factor.

2) Apply the thermal boundary conditions to the circuit in order to compute its average temperature or reference temperature $T_{\text {ref }}$. The thermal boundary conditions to be considered are convection and infrared radiation. There are several ways to model them as a function of the kind of metal housing and environmental conditions, as well as if there is a heat sink attached, as detailed in [14]. Basically, the parameters $h_{\text {conv }}$ and $h_{\text {rad }}$ (in $\mathrm{W} / \mathrm{m}^{2}$ ) are used to model how the heat is delivered from the circuit surfaces (including the metal ground) to the ambient from convection and infrared radiation.

3) Find the power loss for each resonator. It is computed from the equivalent lumped element circuit whose behavior is modeled by the matrix $[A]$ as:

$$
P_{l o s s, i}=\frac{4 P_{i n, a v}}{q_{e} Q_{u} \mathrm{FBW}}[A]_{i, 1}^{-2} .
$$

4) Identify the resonator presenting the highest level of losses. For this resonator, the gradient of temperature per watt between the strip with respect to $T_{r e f}, \Delta T$, is calculated as

$$
\Delta T_{i}=\Delta T_{c, i}+\Delta T_{d, i}=\frac{h}{K}\left(\frac{\mu \overline{\alpha_{c, i}}(f)}{W_{e}(f)}+\frac{\eta \overline{\alpha_{d, i}}(f)}{2 W_{e}(f)}\right)
$$

where $\Delta T_{c}$ and $\Delta T_{d}$ are the temperature gradients generated in the microstrip resonator $i$ due to conductor and dielectric losses, respectively, $K$ is the substrate thermal conductivity, $\overline{\alpha_{c}}$ and $\overline{\alpha_{d}}$ are the average frequencydependent conductor and dielectric power attenuation constants (in $\mathrm{Np} / \mathrm{m}$ ) for each resonator (computed as the power loss per resonator divided by the resonator length) and $W_{e}$ is the thermal effective microstrip width based on a parallel-plate waveguide model [1], [12]. The two additional adimensional parameters $\mu$ and $\eta$ ( $\mu, \eta \exists[0,2]$ ) account for the variation of the power loss with the position in microstrip lines different from matched lines, where $\mu=\eta=1$. For example, at the resonator's open circuit, dielectric losses are maximum and conductor losses minimum, which leads to $\mu=0$ and $\eta=2$, whereas in the resonator's short circuit, the opposite happens leading to $\mu=2$ and $\eta=0$ (see Appendix B).

5) Once $\Delta T_{\max }$ is known, the APHC can be computed as

$$
\begin{aligned}
P_{\max } & =\frac{T_{\max , \text { oper }}-T_{\text {ref }}\left(P_{\max }\right)}{\Delta T_{\max }} \\
& =P_{\text {in }, a v} \times \frac{T_{\max , \text { oper }}-T_{0}}{T_{\max }\left(P_{\text {in }, a v}\right)-T_{0}}
\end{aligned}
$$

where $T_{\max }\left(P_{\text {in,av }}\right)$ is the maximum temperature of the circuit for a particular $P_{i n, a v}, T_{0}$ is the ambient temperature (usually $T_{0}=22^{\circ} \mathrm{C}$ ), and $T_{\max \text {,oper }}$ is the maximum temperature of operation, which can be defined as that temperature where the circuit changes its electrical and mechanical performances (in general, the substrate glass transition temperature) or that temperature which produces an excessive thermal stress in

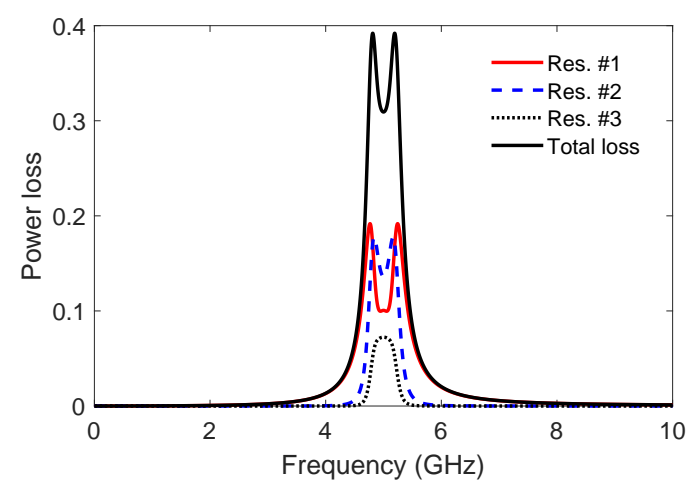

Fig. 5. Power loss per resonator for a 3rd order Chebyshev-type BPF centered at $5 \mathrm{GHz}$ based on $\lambda / 2$ coupled-line resonators. Other parameters: Unloaded quality factor of each resonator $Q_{u}=110, \mathrm{FBW}=5 \%$ and $P_{i n}=1 \mathrm{~W}$.

the circuit. For the second part of (12) it is assumed that the thermal boundary conditions have a linear behaviour with the temperature.

The same example of Fig. 3 is again used in this subsection. The power loss function follows the same shape as that for the voltage magnification, as expected and seen in Fig. 5. Resonator \#1 is limiting the APHC, representing the $50 \%$ of all losses of the filter around the cut-off frequencies. At the center frequency, resonator \#2 is in this case which limits the APHC. Fig. 6 shows the simulated (by using ANSYS Multiphysics) top layer thermal profile of the $\lambda / 2$ coupledline filter for $P_{i n, a v}=2 \mathrm{~W}$ and at $5 \mathrm{GHz}$. As seen, at this frequency resonator \#2 is the hottest element and consequently, it will define the APHC. The maximum simulated gradient of temperature per watt is $14.0^{\circ} \mathrm{C}$, as can be deduced from the figure. Following the theoretical approach previously described, $\Delta T$ is found in resonator $\# 2$ as $\Delta T=7.1^{\circ} \mathrm{C}\left(W_{e}=1.73 \mathrm{~mm}\right.$, $\overline{\alpha_{c}}=2.09 \mathrm{~Np} / \mathrm{m}, \overline{\alpha_{d}}=5.92 \mathrm{~Np} / \mathrm{m}$ ), which gives a maximum gradient for $P_{i n, a v}=2 \mathrm{~W}$ of $14.2^{\circ} \mathrm{C}$, which is a very closed value to that simulated. If the maximum operation temperature of the filter is set to $T_{\max , o p e r}=100^{\circ} \mathrm{C}$, the $\mathrm{APHC}$ at center frequency is found to be $5 \mathrm{~W}$. The same procedure has been repeated for the remaining filters and at the two characteristic frequencies, center frequency $\mathrm{CF}(5 \mathrm{GHz})$, and the frequency where losses are maximum MLF (4.8 and/or 5.2 GHz). Tables VI-VIII show the summary of the simulated and theoretically computed results, for $P_{i n, a v}=2 \mathrm{~W}$ and $h_{c o n v}=9 \mathrm{~W} / \mathrm{m}^{2} \cdot{ }^{\circ} \mathrm{C}$. A relatively good agreement can be observed between the simulated and computed values. It is also clearly observed how the APHC is being limited at MLF, as expected. If the comparison is made among the three kinds of filters, it has been found that there are not important differences regarding their APHC, although the DBR type II filter is the one which presents a higher APHC. This is due to the fact that DBRs type II present a longer length, which reduces the power loss per unit of length, and consequently, $\Delta T$. Another additional reason is the use of via holes in this topology, which can act as heat dissipators. 


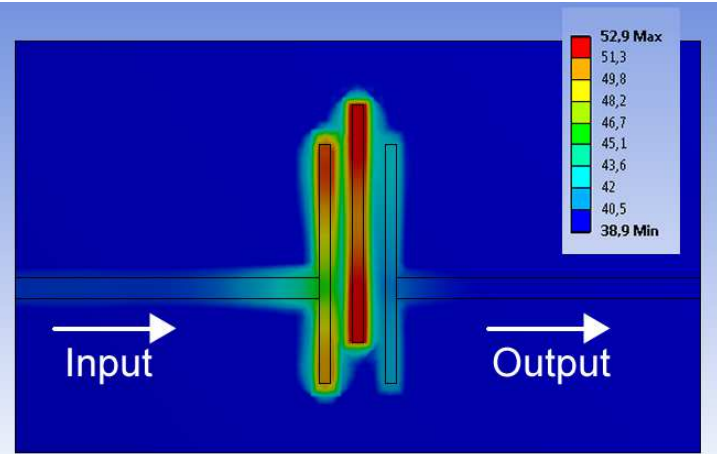

Fig. 6. Simulated thermal profile (top layer) of the $\lambda / 2$ coupled-line filter. $P_{\text {in }, a v}=2 \mathrm{~W}, f=5 \mathrm{GHz}, h_{\text {conv,top }}=h_{\text {conv }, \text { botton }}=9 \mathrm{~W} / \mathrm{m}^{2}$ and $K=0.35 \mathrm{~W} /\left(\mathrm{m} \cdot{ }^{\circ} \mathrm{C}\right)$.

TABLE VI

SUMMARIZE OF THE ELECTRO-THERMAL ANALYSIS. COUPLED-LINE FILTER. $P_{\text {in }, a v}=2 \mathrm{~W}, h_{\text {con } v}=9 \mathrm{~W} / \mathrm{M}^{2} \cdot{ }^{o} \mathrm{C}, T_{\max , \text { oper }}=100{ }^{\circ} \mathrm{C}$

\begin{tabular}{c|cc|cc}
\hline \hline & \multicolumn{2}{|c|}{ Simulated (ANSYS Mult.) } & \multicolumn{2}{|c}{ Theoretically computed } \\
\cline { 2 - 5 } & CF & MLF & CF & MLF \\
\hline \hline$\Delta T_{\max }\left({ }^{\circ} \mathrm{C} / \mathrm{W}\right)$ & 7.0 & 12.4 & 7.1 & 10.1 \\
\hline$T_{\operatorname{ref}}\left({ }^{\circ} \mathrm{C}\right)$ & 39 & 48 & 41 & 47 \\
\hline$T_{\max }\left({ }^{\circ} \mathrm{C}\right)$ & 53 & 73 & 55 & 67 \\
\hline APHC $(\mathrm{W})$ & 5.0 & 3.0 & 4.7 & 3.4 \\
\hline
\end{tabular}

\section{EXPERIMENTAL RESULTS}

In order to validate and confirm the theoretical study regarding the power handling capability of microstrip filters, two measurement campaigns have been developed: one for the PPHC study and another for the APHC one. The three prototype filters of Fig. 1 have been implemented on substrate Neltec 4380, whose characteristics are specified in Section II. The whole surface of the three circuits is set to be the same $\left(50 \times 30 \mathrm{~mm}^{2}\right)$ for a fair comparison with respect to the APHC, since different whole surfaces would lead to different thermal boundary conditions. The simulated and measured S-parameter responses are plotted in Fig. 7, where a good agreement between them can be observed. The insertion loss has been lower than $2.8 \mathrm{~dB}$ for all filters at the measured center frequency, which has been $5.1 \mathrm{GHz}$. The filters based on DBRs present a higher selectivity due to the pair of transmission zeros placed at each side of the passband, generated, precisely, by the dual-behaviour (one pole and two transmission zeros per resonator) of the resonators forming the filter. The $\lambda / 2$ coupled-line filter presents a close-to-band transmission zero at the upper band due to the cross-coupling between the first and third resonator, and a lower band transmission zero generated by the stub effect of the first resonator.

\section{A. PPHC Measurement Campaign}

To validate the PPHC, a measurement campaign has been carried out at the European High-Power RF Space Laboratory (Valencia, Spain). Several methods have been used for the corona discharge detection: third harmonic detection, nulling of the forward/reverse power at the operation frequency and electron probe. The applied signal to the circuits has been
TABLE VII

SUMMARIZE OF THE ELECTRO-THERMAL ANALYSIS. DBR TYPE I FILTER. $P_{i n, a v}=2 \mathrm{~W}, h_{c o n v}=9 \mathrm{~W} / \mathrm{M}^{2} \cdot{ }^{o} \mathrm{C}, T_{\max , o p e r}=100{ }^{\circ} \mathrm{C}$.

\begin{tabular}{c|cc|cc}
\hline \hline & \multicolumn{2}{|l|}{ Simulated (ANSYS Mult.) } & \multicolumn{2}{|l}{ Theoretically computed } \\
\cline { 2 - 5 } & CF & MLF & CF & MLF \\
\hline \hline$\Delta T_{\max }\left({ }^{\circ} \mathrm{C} / \mathrm{W}\right)$ & 8.0 & 13.5 & 8.6 & 13.8 \\
\hline$T_{\text {ref }}\left({ }^{\circ} \mathrm{C}\right)$ & 40 & 44 & 41 & 47 \\
\hline$T_{\max }\left({ }^{\circ} \mathrm{C}\right)$ & 56 & 71 & 58 & 74 \\
\hline APHC $(\mathrm{W})$ & 4.6 & 3.2 & 4.3 & 3.0 \\
\hline
\end{tabular}

TABLE VIII

SUMMARIZE OF THE ELECTRO-THERMAL ANALYSIS. DBR TYPE II FILTER. $P_{i n, a v}=2 \mathrm{~W}, h_{c o n v}=9 \mathrm{~W} / \mathrm{M}^{2} \cdot{ }^{\circ} \mathrm{C}, T_{\max , o p e r}=100{ }^{\circ} \mathrm{C}$.

\begin{tabular}{c|cc|cc}
\hline \hline & \multicolumn{2}{|c|}{ Simulated (ANSYS Mult.) } & \multicolumn{2}{|l}{ Theoretically computed } \\
\cline { 2 - 5 } & CF & MLF & CF & MLF \\
\hline \hline$\Delta T_{\max }\left({ }^{\circ} \mathrm{C} / \mathrm{W}\right)$ & 4 & 11.5 & 7.0 & 10.5 \\
\hline$T_{\text {ref }}\left({ }^{\circ} \mathrm{C}\right)$ & 38 & 40 & 41 & 47 \\
\hline$T_{\max }\left({ }^{\circ} \mathrm{C}\right)$ & 46 & 63 & 55 & 68 \\
\hline APHC $(\mathrm{W})$ & 6.5 & 3.8 & 4.7 & 3.4 \\
\hline
\end{tabular}

a pulsed signal with a width of $20 \mu$ s and a duty cycle of $2 \%$ with a carrier frequency of $5.1 \mathrm{GHz}$. This frequency corresponds to the measured center frequency of all filters. These pulsed signal characteristics avoid any self-heating effect in the device, whereas the pulse width is wide enough to assume that the pulse breakdown threshold converges to the CW one. Moreover, a radioactive source (Strontium-90) has been used to generate an electron seed which facilitates the measurement detection. The three implemented filters have been measured at ambient temperature $\left(22^{\circ} \mathrm{C}\right)$ in a pressured controlled chamber from 1 to 1013 mbar in order to get their respectives Paschen curves. The high-power measurement testbed has been calibrated for input power levels in the range $1-200 \mathrm{~W}$.

Fig. 8 shows the simulated and measured Paschen curves. The power level threshold are always higher at the center frequency for the three implemented filters, as expected. The DBR type I filter shows the lowest power thresholds whereas the DBR type II filter the highest ones, as seen in Fig. 9. These results confirm the conclusions previously reached in Section II. The critical pressure (the pressure where PPHC reaches its minimum value) has been around 10 mbar for all devices, which is an expected value for such devices working at $5 \mathrm{GHz}$. For pressures lower than the critical one, the power threshold levels start increasing due to the lack of air particles, which avoids any corona discharge to be produced. For this pressure regime (approaching to vacuum conditions), multipactor breakdown (i.e., electron avalanche phenomenon) may limit the PPHC, although microstrip seems to be a technology highly resistant to multipactor discharge because it is an open structure which makes difficult the creation of a well-defined trajectory of electrons [26].

The measured results shown in Fig. 8 have always given higher power level values as compared to simulations. This can be due to different factors: the measured filters have presented a bit higher insertion loss levels than those simulated, 


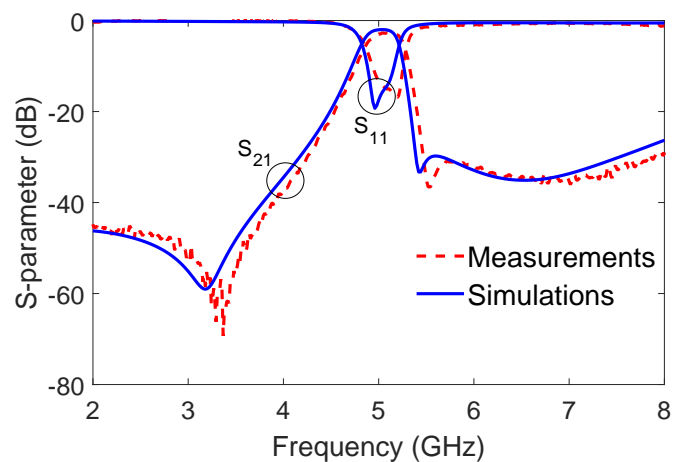

(a)

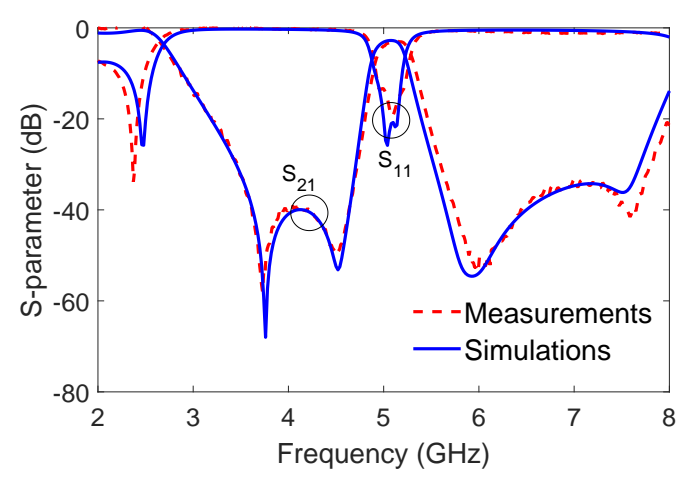

(b)

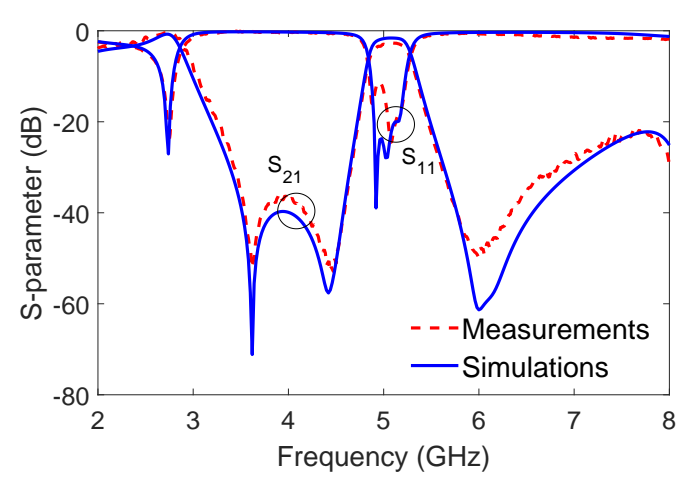

(c)

Fig. 7. Full-wave simulated and measured responses of the three implemented microstrip filters. (a) $\lambda / 2$ coupled-line filter. (b) Filter based on DBRs type I. (c) Filter based on DBRs type II.

which means that the resonators $Q_{u}$ has been lower than that expected, leading to lower VMF values and consequently, to higher PPHC. On the other hand, the measurement test bed has been calibrated by using N-type connectors, whereas the filters under test are connectorized by means of SMA connectors. The losses from the calibration planes up to the microstrip feeding lines (which are taken as a reference in simulations) has been estimated around $0.2 \mathrm{~dB}$, consequently, the applied power levels to the circuits under test could have been around $4.5 \%$ lower than those reported. In addition, the uncertainty of the measured power levels for this test bed at the operation frequency $(5 \mathrm{GHz}$ ) has been estimated in $\pm 4 \%$. All these effects give an accumulated uncertainty in the measured results of Fig. 8 of up to $8 \%$.
A video camera was placed inside the pressure chamber in order to record the corona sparks during the measurements. Fig. 10 shows the capture at the time of a corona discharge for the $\lambda / 2$ coupled-line filter. It can be seen how the corona breakdown happens at Resonators \#1 and \#2 at their openended terminations. For the DBR type I filter, at ambient pressure (i.e., 1013 mbar) the pulsed signal was kept for some seconds when a corona discharge occurred with the purpose of destroying the filter (this filter was chosen for this test because it was the only one which afforded less than $200 \mathrm{~W}$ at ambient pressure). The filter was not destroyed but one of its resonators (resonator \#1) started being seriously damaged, as Fig. 11 shows, where it can be appreciated the degradation of copper and a slight peel-off from the substrate.

\section{B. APHC Measurement Campaign}

With respect to the APHC measument campaign, without the need of using a pressure chamber and since the power levels to be analyzed in these tests are much lower than those for PPHC, a lesser complex measurement setup has been arranged with a power level range up to $3 \mathrm{~W}$, which is more than enough for the filters under study. An infrared camera model SC7600BB from FLIR Systems has been used to measure the thermal maps of the circuits. It has been placed 1-meter above the circuits. An infrared camera gives much more information than thermal probes (thermocoupled), and in addition, it does not alter the electromagnetic field distribution of the devices under test, i.e., it is a non-intrusive measured method. In this measurement setup, a CW signal has been applied to the circuit at the frequencies of interest. For all circuits under analysis the thermal steady state behaviour has been reached after 5 minutes the signal generator is switched on. The circuits in this measurement setup have been suspended $5 \mathrm{~cm}$ above the table, and thus, all their layers have been subject to natural convection. To compute the thermal map from the infrared radiation a constant infrared emissivity of 0.85 has been considered in all the circuit surface, which matches well the emissivity of the substrate, but it overestimates that of the metal, so, the temperature cannot be evaluated properly in the metal surfaces, as usually happens when working with infrared cameras. This is not a problem since the maximum temperature can be just evaluated in the metal-to-dielectric transition without loss of accuracy. The equivalent convection coefficient of the laboratory environment has been estimated by means of the measured and simulated cooling time curves as $h_{\text {conv }}=9 \mathrm{~W} / \mathrm{m}^{2} \cdot{ }^{\circ} \mathrm{C}$. The temperature of the laboratory has been $21^{\circ} \mathrm{C}$.

Fig. 12 shows the measured thermal maps of the three implemented filters for $P_{i n, a v}=2 \mathrm{~W}$ and at the frequencies where their losses have been maximum. For all cases, resonator \#1 is limiting the APHC as previously deduced in Section II. In addition, from these measurements it can be also concluded that dielectric losses are more important than conductor ones, since the hot spots are placed around the maximum of electric field strength. This result agrees well with the computed $\overline{\alpha_{c}}$ and $\overline{\alpha_{d}}$ if one takes as an example the $\lambda / 2$ coupled-line filter, where it has been revealed that 


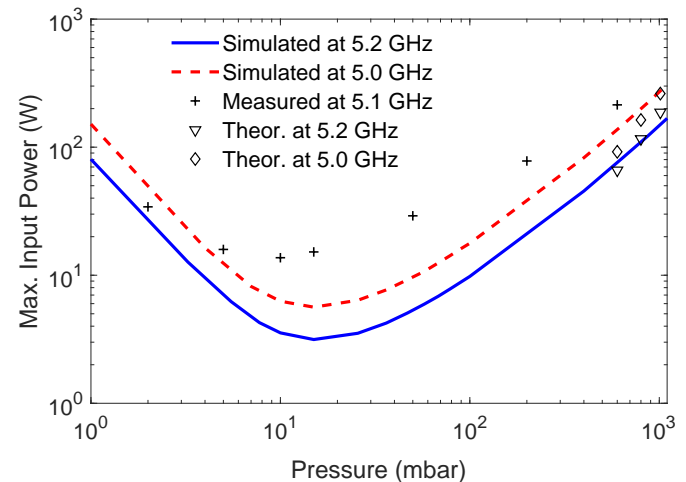

(a)

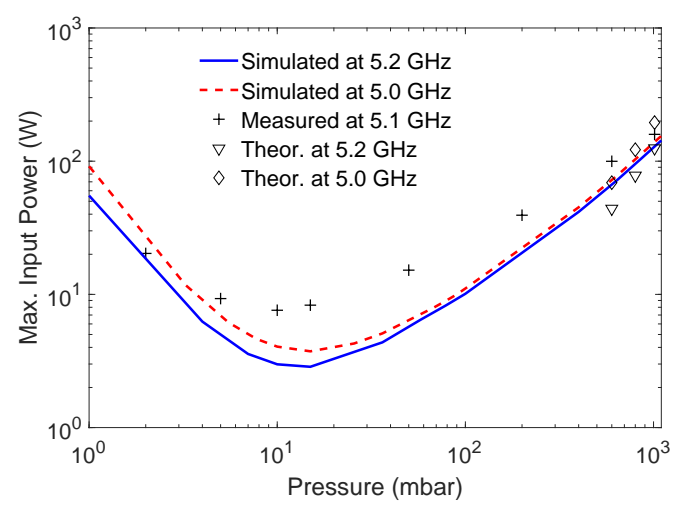

(b)

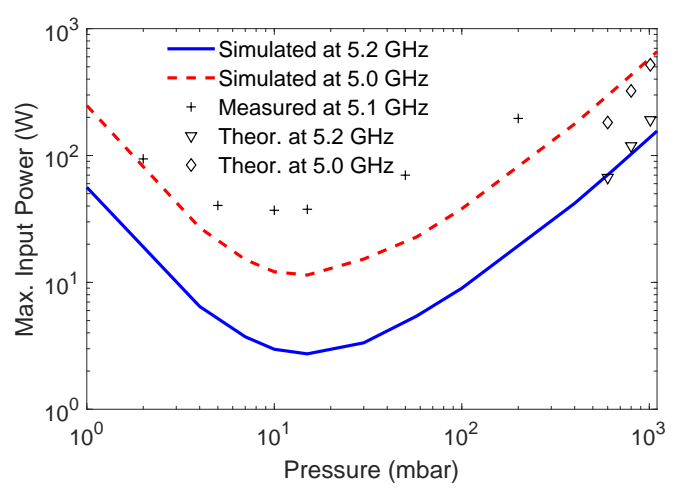

(c)

Fig. 8. Simulated and measured Paschen curves for the implemented thirdorder filters. (a) $\lambda / 2$ coupled-line filter. (b) Filter based on DBRs type I. (c) Filter based on DBRs type II. The simulated curves at 5.2 and $5.0 \mathrm{GHz}$ correspond to the frequencies where the voltage magnification is maximum and to the center frequencies of the simulated filter responses, respectively, whereas the measured curve at $5.1 \mathrm{GHz}$ corresponds to the measured center frequency of the implemented filters. The theoretical computed values are plotted for pressures higher than 600 mbar (where the prediction range is more accurate).

dielectric losses correspond to the $74 \%$ of the whole losses. The APHC can be calculated according to (12) by knowing the measured maximum temperature for each filter for a particular $P_{i n, a v}$ (in this case, $2 \mathrm{~W}$ ). For this, it must be assumed that the thermal boundary conditions have a linear behaviour with the temperature. Table IX summarizes the measured results. These

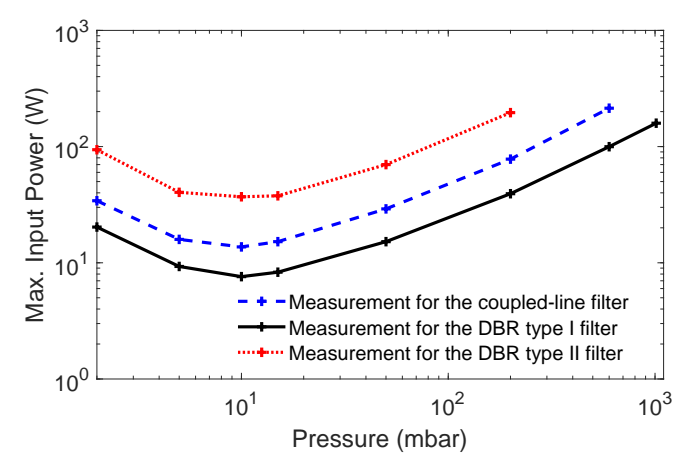

Fig. 9. Measured Paschen curves at 5.1 GHz for the three implemented filters.

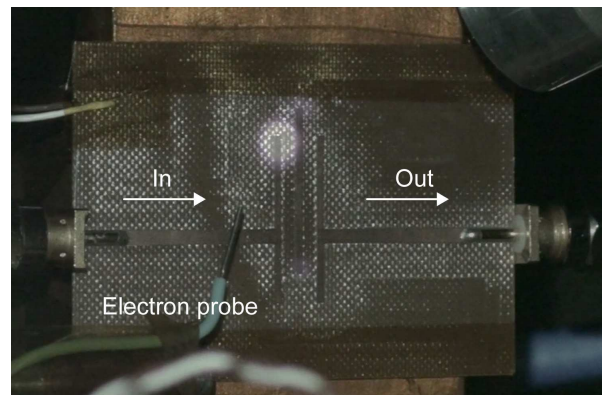

Fig. 10. Capture at the time of a corona discharge for the $\lambda / 2$ coupled-line filter. The electron probe is placed $5 \mathrm{~cm}$ above the filter in order to avoid any interference with the filter behavior.

results are in a reasonable good agreement and follow the same trend than those theoretically computed and simulated, and previously addressed in Section II-B. As confirmed by these measurements, these three kinds of filters provide similar APHC performances, so, their differences regarding the power handling are rather with respect to PPHC.

The values found for APHC and PPHC define the kind of signals that these filters can afford in moderate-to-high power applications according to the signal's peak-to-average power ratio. This is a characteristic parameter of communication signals presenting multiple carriers which can be added in phase in some intervals of time (e.g., OFDM). For instance, in the filters under analysis the obtained APHC values are much lower than those found for PPHC for pressures higher than 100 mbar, which may allow signals with a relatively high peak-toaverage power ratio to work. However, for pressures below 50 mbar, both APHC and PPHC have presented values of the same order of magnitude, consequently, either the signal's peak-to-average power ratio should be close to $0 \mathrm{~dB}$ to avoid any issue, or the signal average power should be considerably reduced (to still keep the signal's peak power below PPHC).

\section{Discussion}

Both the theoretical PPHC and APHC analyses, along with their respective physical limiting factors, corona breakdown and electro-thermal effects, have provided results which are in a moderate good agreement with those found in simulations and in the two developed measurement campaigns. It should be noted that in all theoretical computations the ideal behavioral 


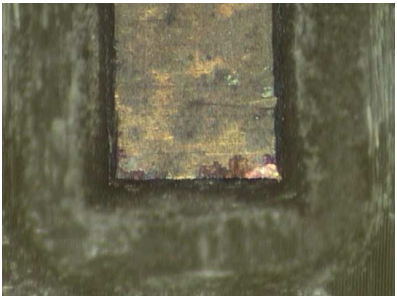

Fig. 11. Photograph by using a microscope of the damage suffered by the resonator \#1 when a corona discharge has occurred for the DBR Type I filter. Please note that resonator \#1 is the limiting element at the center frequency of this filter due to its low $\chi$.

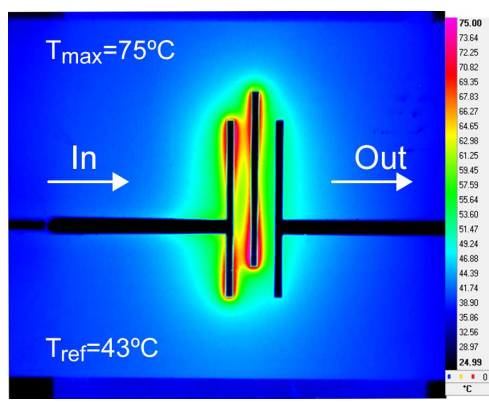

(a)

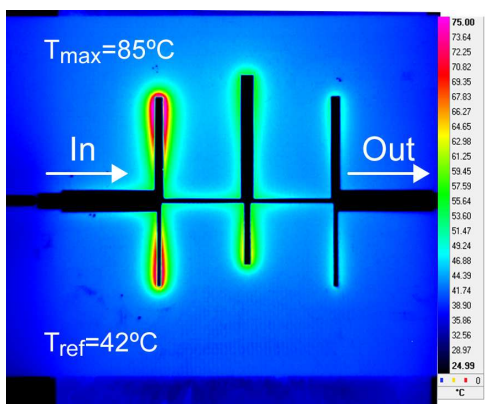

(b)

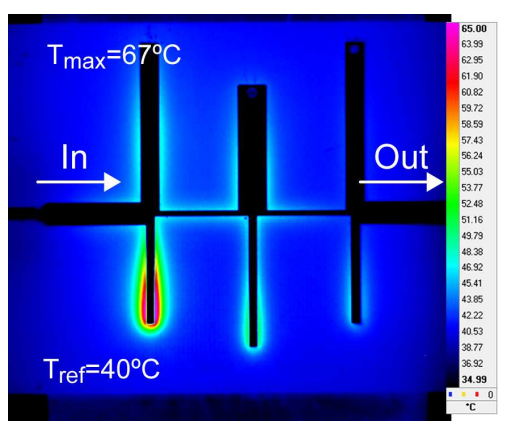

(c)

Fig. 12. Measured thermal maps for the three implemented filters at the frequencies where losses have been maximum and for $P_{i n, a v}=2 \mathrm{~W}$. (a) $\lambda / 2$ coupled-line filter. (b) Filter based on DBRs type I. (c) Filter based on DBRs type II.

matrix [A] (impedance/admittance matrix) has been used for all filters, that in this case has been defined by the Chebyshev filter coefficients. This provides a very fast and easy computation of the PPHC and APHC, as demonstrated along the paper, which may be useful for a practitioner engineer, knowing well that there may still have some differences with respect to the fabricated device results. If a higher accuracy were still
TABLE IX

CW MEASUREMENTS OF THE THREE IMPLEMENTED FILTERS

\begin{tabular}{c|c|c|c|c}
\hline \hline Filter topology & freq. $(\mathbf{G H z})$ & $T_{\max }$ & $T_{\text {ref }}$ & APHC (W) \\
\hline \hline \multirow{2}{*}{ Coupled-line filter } & 5.1 & $62(55)$ & $40(41)$ & $3.9(4.7)$ \\
& 5.27 & $75(67)$ & $43(47)$ & $2.9(3.4)$ \\
\hline \multirow{2}{*}{ DBR type I filter } & 5.1 & $55(58)$ & $40(41)$ & $4.6(4.3)$ \\
& 5.27 & $85(74)$ & $42(47)$ & $2.6(3.0)$ \\
\hline \multirow{2}{*}{ DBR type II filter } & 5.1 & $50(55)$ & $40(41)$ & $5.4(4.7)$ \\
& 5.24 & $67(68)$ & $40(47)$ & $3.5(3.4)$ \\
\hline
\end{tabular}

The maximum temperature of operation for computing APHC has been assumed to be $100^{\circ} \mathrm{C}$.

Between brackets, the temperatures theoretically computed in Section II-B at CF and MLF.

desired for the theoretical computations, one way to achieve it may be by extracting the matrix [A] of the implemented filter from full-wave simulations, and using this extracted matrix in all computations. In fact, in most of technologies, and especially, in microstrip technology, after implementing the filter layout, the theoretical (and ideal) filter response (in terms of ideal location of poles and zeros) is usually lost, due to frequency dispersion, discontinuities, harmonic spurious bands and/or the inclusion of additional performances in the filter response, such as TZs generation. This may modify the voltage distributions along the resonators, as well as the power dissipated by them, conditioning, to a greater or lesser extent, the theoretical predictions.

As said in the beginning of the paper, the theoretical predictions developed along the paper are focused on narrowto-moderate bandwidth filters (up to 20\%). This is mainly because of the way $\chi$ parameter is computed (taking into account the current and voltage distributions of isolated resonators) and the assumption that the coupling coefficients (which define the matrix [A]) are frequency-invariant along the filter bandwidth. The former could be addressed since the exact form of voltage and current distributions can be also computed for wider bandwidths (and therefore, wider couplings) [27]. The latter, however, effectively puts a limitation in the developed theoretical models. Anyway, microstrip filters with bandwidths higher than $20 \%$, a priori, do not represent an issue regarding PPHC, since the voltage magnification per resonator is considerably reduced in those situations, leading to an enhancement of PPHC, and putting the PPHC limitation in other parts of the circuit board, for instance, in the coaxialto-microstrip transitions.

Specifying now for the electro-thermal analysis, linked to the APHC study, even if the theoretically predicted results have shown a reasonable good agreement with simulations and measurements, elements like via holes and inverters by means of transmission lines (which can propagate heat flow and are both used in the DBR type II filter) can put additional thermal constraints not considered in the electro-thermal model. In those cases, the procedure described in Section II-B combined with a thermal transmission line model [13], [28] can be a good compromise in terms of accuracy and computation cost between the theoretical model here described and a multiphysics simulation. 


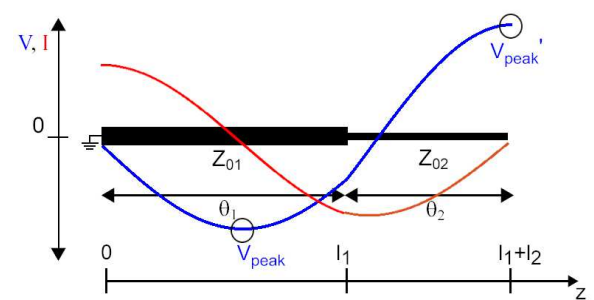

Fig. 13. DBR type II along with the voltage and current distributions at resonance.

\section{CONCLUSion}

The average and peak power handling capability of microstrip filters have been addressed in this paper. Closed-form expressions have been computed to predict both the PPHC and $\mathrm{APHC}$ as a function of the geometrical parameters of the microstrip filter resonators. This investigation has been focused on three filtering topologies very well known in the literature, even though some guidelines have been also provided to extrapolate the developed theoretical model to other filtering structures. Three bandpass filters have been designed and implemented at $5 \mathrm{GHz}$ for verification purposes. The PPHC and APHC of these filters have been validated by means of two measurement campaigns which have been carried out, where Paschen curves and thermal maps have been obtained for each filter. The measured results have corroborated the conclusions obtained along the paper. One of the implemented filters has afforded more than $200 \mathrm{~W}$ of peak power at ambient pressure, whereas all filters have presented a similar APHC of around 4$5 \mathrm{~W}$ at the center frequency. According to this research study, it is possible to take into account in the filter design step the power handling capability in order for it to be maximized, as well as the kind of signal that the filter can afford regarding the signal's peak-to-average power ratio.

\section{APPENDIX A}

COMPUTATION OF $\chi$

In this appendix, the $\chi$ function, which characterizes the voltage magnification, and consequently, the PPHC of a resonator as a function of its geometrical parameters, is computed for the DBR type II. This procedure can be easily extrapolated to other kinds of transmission line resonators.

The first step is to obtain the voltage and current standing waves at resonance, with the purpose of computing later the stored energy by the resonator as a function its geometrical parameters. Fig. 13 shows the DBR type II, where all its transmission line parameters have been previously defined in Section II. In the first line section $\left(0 \leq z \leq l_{1}\right)$, the voltage and current distributions can be expressed from the boundary conditions as

$$
\begin{aligned}
& V_{1}(z)=j V_{\text {peak }} \sin (\beta z) \\
& I_{1}(z)=\frac{V_{\text {peak }}}{Z_{01}} \cos (\beta z)
\end{aligned}
$$

where $\beta$ is the propagation constant, whereas in the second line section $\left(l_{1} \leq z \leq l_{1}+l_{2}\right)$

$$
\begin{aligned}
& V_{2}(z)=V_{\text {peak }}^{\prime} \cos \left(\beta\left(z-l_{1}-l_{2}\right)\right) \\
& I_{2}(z)=j \frac{V_{\text {peak }}^{\prime}}{Z_{02}} \sin \left(\beta\left(z-l_{1}-l_{2}\right)\right)
\end{aligned}
$$

At $z=l_{1}$, there must be voltage and current continuity between the two sections. This gives the relation between $V_{\text {peak }}$ and $V_{\text {peak }}^{\prime}$ as well as the resonance condition of this resonator, which is

$$
\frac{Z_{02}}{Z_{01}}=-\tan \left(\theta_{1}\right) \tan \left(-\theta_{2}\right)
$$

Now, the stored energy by this resonator at resonance can be computed as [23], [24]

$$
\begin{aligned}
& W_{\text {distr }}=W_{\text {distr,el }}+W_{\text {distr,mag }}=2 W_{\text {distr,el }} \\
& =2\left[\frac{1}{4} \int_{0}^{l_{1}} C_{1}\left|V_{1}\right|^{2} d z+\frac{1}{4} \int_{l_{1}}^{l_{1}+l_{2}} C_{2}\left|V_{2}\right|^{2} d z\right] \\
& =\frac{V_{\text {peak }}^{2}}{4 \omega_{0} Z_{01}}\left(\theta_{1}-\frac{1}{2} \sin 2 \theta_{1}\right)+\frac{V_{\text {peak }}^{\prime 2}}{4 \omega_{0} Z_{02}}\left(\theta_{2}+\frac{1}{2} \sin 2 \theta_{2}\right)
\end{aligned}
$$

where $C_{1}$ and $C_{2}$ are the capacitances per unit length of each section, and $W_{d i s t r, e l}$ and $W_{d i s t r, m a g}$ are the electric and magnetic stored energies which are equal to each other at resonance. Once $W_{\text {distr }}$ is computed, by making (3) equal to (16), and after some straightforward algebraical manipulation, it is obtained $V_{\text {peak,i }}$ (eq. (4)) as a function of: the filtering response, the applied power $P_{i n}$ and the geometrical characteristics of the resonator $i$ by means of the here defined $\chi$ parameter.

\section{APPENDIX B}

\section{COMPUTATION OF THE AVERAGE POWER ATTENUATION} CONSTANT

In this appendix, the computation of the average dielectric and conductor power attenuation constants for a transmission line resonator is addressed. It is again, taken as an example, the DBR type II.

The dielectric power loss distribution along the resonator follows the pattern of the voltage distribution, and can therefore be written as

$$
\begin{array}{lr}
P_{d, 1}=A \sin ^{2}(\beta z) & 0 \leq z \leq l_{1} \\
P_{d, 2}=B \cos ^{2}\left(\beta\left(z-l_{1}-l_{2}\right)\right) & l_{1} \leq z \leq l_{1}+l_{2}
\end{array}
$$

where $A$ and $B$ are the maximum dielectric power loss per unit length in each section, and are related to each other as $A=\left(\cos \theta_{2} / \sin \theta_{1}\right)^{2} \times B$, where it is assumed power loss continuity at $z=l_{1}$. So, the dielectric power loss per unit length varies in this resonator between 0 and $\max (A, B)$, that for the DBR type II is normally $B$. 
The total dielectric power loss per resonator $P_{\text {loss }, d, i}$ can be computed by integrating (17a) and (17b) along the two length sections, obtaining

$$
\begin{aligned}
& P_{\text {loss }, d, i}= \\
& \frac{B}{2} \times\left[\left(\frac{\cos \theta_{2}}{\sin \theta_{1}}\right)^{2}\left(l_{1}-\frac{1}{2 \beta} \sin 2 \theta_{1}\right)+\left(l_{2}+\frac{1}{2 \beta} \sin 2 \theta_{2}\right)\right]
\end{aligned}
$$

$P_{\text {loss }, d, i}$ is, in turn, computed from (10) (by using $Q_{u, d}$ instead of $Q_{u}$ ). The term of (18) accompanying $B / 2$ can be treated as a resonator length factor. According to this, the average dielectric power attenuation constant can be expressed simply as $\overline{\alpha_{d, i}}=B / 2$, leading to

$$
\begin{aligned}
& \overline{\alpha_{d, i}}= \\
& P_{\text {loss }, d, i} /\left[\left(\frac{\cos \theta_{2}}{\sin \theta_{1}}\right)^{2}\left(l_{1}-\frac{1}{2 \beta} \sin 2 \theta_{1}\right)+\left(l_{2}+\frac{1}{2 \beta} \sin 2 \theta_{2}\right)\right]
\end{aligned}
$$

Therefore, the dielectric power loss per unit length varies between 0 and $2 \overline{\alpha_{d, i}}$ along the resonator length, as stated in Section II-B. This defines the location of the maximum gradient of temperature (linked to dielectric losses) along the resonator, which is at $z=l_{1}+l_{2}$.

In the same way, the average conductor power loss $\overline{\alpha_{c, i}}$ can be computed as

$$
\begin{aligned}
& \overline{\alpha_{c, i}}= \\
& P_{\text {loss }, c, i} /\left[\left(l_{1}+\frac{1}{2 \beta} \sin 2 \theta_{1}\right)+\left(\frac{\cos \theta_{1}}{\sin \theta_{2}}\right)^{2}\left(l_{2}-\frac{1}{2 \beta} \sin 2 \theta_{2}\right)\right]
\end{aligned}
$$

The conductor power loss per unit length along the resonator length varies, consequently, between 0 and $2 \overline{\alpha_{c, i}}$, being maximum at $z=0$.

\section{ACKNOWLEGMENT}

The authors would like to acknowledge Val Space Consortium for its contribution-Laboratories funded by the European Regional Development Fund-A way of making Europe.

\section{REFERENCES}

[1] R. Garg, I. J. Bahl, and M. Bozzi, Microstrip lines and slotlines. Artech House, 3 ed., 2013.

[2] R. K. Mongia, I. J. Bahl, P. Barthia, and J. Hong, $R F$ and Microwave Coupled-Line Circuits. Norwood, MA: Artech House Microwave Library, 2 ed., 2007.

[3] J. S. Hong, "Reconfigurable planar filters," IEEE Microw. Mag., vol. 10, pp. 73-83, Oct. 2009.

[4] G. Rebeiz et al., "Tuning in to rf mems," IEEE Microw. Mag., vol. 10, pp. $55-72$, Oct. 2009.

[5] R. Gomez-Garcia, M. Sanchez-Soriano, K. Tam, and Q. Xue, "Flexible filters: Reconfigurable-bandwidth bandpass planar filters with ultralarge tuning ratio," IEEE Microw. Mag., vol. 15, pp. 43-54, July 2014.

[6] J. S. Hong, Microstrip Filter for RF/Microwave Applications. New Jersey: John Wiley and Sons, inc., 2nd ed., 2011.

[7] R. Gómez-García and J. I. Alonso, "Design of sharp-rejection and lowloss wide-band planar filters using signal-interference techniques," IEEE Microw. Wireless Compon. Lett., vol. 15, pp. 530-532, Aug. 2005.

[8] M. A. Sánchez-Soriano, E. Bronchalo, and G. Torregrosa-Penalva, "Compact UWB bandpass filter based on signal interference techniques," IEEE Microw. Wireless Compon. Lett., vol. 19, pp. 692-694, Nov. 2009.
[9] W. J. Feng, W. Q. Che, Y. M. Chang, S. Y. Shi, and Q. Xue, "High selectivity fifth-order wideband bandpass filters with multiple transmission zeros based on transversal signal-interaction concepts," IEEE Trans. Microw. Theory Techn., vol. 61, Jan. 2013.

[10] L. Zhu, S. Sun, and R. Li, Microwave bandpass filters for wideband communications. New Jersey: John Wiley and Sons, inc., 2012.

[11] S. Sun and L. Zhu, "Multimode-resonator-based bandpass filters," IEEE Microw. Mag., vol. 10, pp. 88 -98, Apr. 2009.

[12] L.-S. Wu, X.-L. Zhou, W.-Y. Yin, M. Tang, and L. Zhou, "Characterization of average power handling capability of bandpass filters using planar half-wavelength microstrip resonators," IEEE Microw. Wireless Compon. Lett., vol. 19, pp. 686-688, Nov. 2009.

[13] L.-S. Wu, J. Mao, W.-Y. Yin, and M. Tang, "Average power handling capability of quarter-wavelength microstrip stepped-impedance resonator bandpass filter," in Microwave Symposium Digest (MTT), 2012 IEEE MTT-S International, pp. 1-3, IEEE, 2012.

[14] M. Sanchez-Soriano, Y. Quere, V. Le Saux, C. Quendo, and S. Cadiou, "Average power handling capability of microstrip passive circuits considering metal housing and environment conditions," IEEE Trans. Compon., Packag., Manuf. Technol., vol. 4, pp. 1624-1633, Oct. 2014.

[15] M. Yu, "Power-handling capability for rf filters," IEEE Microw. Mag., vol. 8, pp. 88-97, Oct. 2007.

[16] R. J. Cameron, C. M. Kudsia, and R. R. Mansour, Microwave Filters for Communication Systems. Hoboken, New Jersey.: John Wiley \& Sons, Inc, 2 ed., 2018.

[17] F. J. Perez et al., "Rigorous investigation of RF breakdown effects in high power microstrip passive circuits," Proc. IEEE MTT-S Int. Microwave Symp. Dig., pp. 833-836, Jun. 2009.

[18] F. J. Perez, S. Anza, M. Mattes, et al., "RF breakdown analysis in microstrip structures," Proc. International Workshop on Multipactor, Corona and Passive Intermodulation (MULCOPIM2011), pp. 1-7, Sep. 2011.

[19] C. Quendo, E. Rius, and C. Person, "Narrow bandpass filters using dual-behavior resonators," IEEE Trans. Microw. Theory Techn., vol. 51, pp. 734-743, Mar. 2003.

[20] C. Quendo, E. Rius, and C. Person, "Narrow bandpass filters using dualbehavior resonators based on stepped-impedance stubs and differentlength stubs," IEEE Trans. Microw. Theory Techn., vol. 52, pp. 10341044, Mar. 2004.

[21] C. Ernst and V. Postoyalko, "Prediction of peak internal fields in directcoupled-cavity filters," IEEE Trans. Microw. Theory Techn., vol. 51, pp. 64-73, Jan. 2003.

[22] F. M. Vanin, F. D. Paolis, and D. Schmitt, "Resonator voltage prediction in microwave bandpass filters," IEEE Trans. Microw. Theory Techn., vol. 63, pp. 397-402, Feb. 2015.

[23] R. E. Collin, Foundations for microwave engineering. John Wiley \& Sons, 2007.

[24] M. Sanchez-Soriano, E. Bronchalo, and G. Torregrosa-Penalva, "Parallel-coupled line filter design from an energetic coupling approach," IET Microw., Antennas and Prop., vol. 5, pp. 568-575, Apr. 2011.

[25] W. Woo and J. DeGroot, "Microwave absorption and plasma heating due to microwave breakdown in the atmosphere," IEEE Physical Fluids, vol. 27 , no. 2, pp. 475-487, 1984

[26] V. E. Semenov et al., "Simulations of multipactor thresholds in shielded microstrip lines," Journal of Physics D: Applied Physics, vol. 42, pp. 17, 2009.

[27] E. Bronchalo, M. Sanchez-Soriano, G. Torregrosa, and A. Coves, "Theoretical study of the coupling factor of open-ended coupled transmission lines at first resonant frequencies under quasi-TEM propagation," in Progress In Electromagnetics Research Symposium, pp. 596-600, 2013.

[28] S. Ni, M. Tang, L.-S. Wu, and J. Mao, "An analytical approach for electrical and thermal simulation of branch-line coupler," in 2017 IEEE MTT-S International Microwave Symposium (IMS), pp. 562-564, June 2017. 


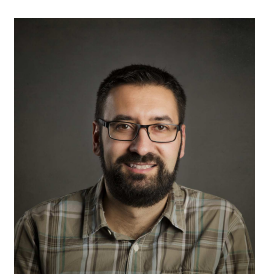

Miguel A. Sánchez-Soriano (S'09-M'13) was born in Yecla (Murcia), Spain, in 1984. He received the Telecommunications Engineer degree (with a Special Award) and the Ph.D degree on Electrical Engineering from the Miguel Hernandez University (UMH), Spain, in 2007 and 2012, respectively.

In 2007 he joined the Radiofrequency Systems Group, UMH, as a research assistant. He was a visiting researcher with the Microwaves Group at HeriotWatt University, Edinburgh, UK, in 2010. In January 2013 he joined the LabSTICC group (Université de Bretagne Occidentale, Brest, France) as a Postdoctoral Researcher, where he worked for 2 years. From January 2015 to September 2015, he was a "Juan de la Cierva" research fellow at the Grupo de Aplicaciones de Microondas (GAM) (Technical University of Valencia, Spain). Since September 2015, he has been assistant professor at the University of Alicante. His research interests cover the analysis and design of microwave planar devices, especially filters and their reconfigurability, and the multiphysics study of high frequency devices.

Dr. Sánchez-Soriano was the recipient of the runner-up HISPASAT award to the Best Spanish Doctoral Thesis in New Applications for Satellite Communications, awarded by the Spanish Telecommunication Engineers Association (COIT/AEIT), and of the Extraordinary Ph.D award from the Miguel Hernández University. He serves as an Associate Editor for the journals IEEE Transactions on Microwaves, Theory and Techniques and IET Microwaves, Antennas and Propagation, and as a regular reviewer for more than ten journals and several IEEE international conferences, including the IEEE Microwave and Wireless Components Letters, IET Electronics Letters and IEEE Access.

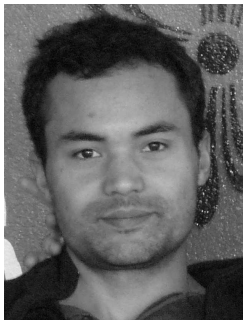

Yves Queré (M'02) was born in Lannion, France, in 1980. He received the Electrical Engineer degree and the Ph.D degree on Electrical Engineering from the University of Brest, France, in 2003 and 2006, respectively.

Since 2007, he has been an Assistant Professor with the Electronic Department, University of Brest, France. He also conducts research with Microwaves Group of the Lab-STICC Laboratory, France. He was visiting researcher in 2013 at CNRS International NTU THALES Research Alliance, Nanyang technological University, Singapore and in Cranfield University for 6 months in 2015. His research activities concern the microwave passive components (Filters, Antennas) and are especially focused on electromagnetic, antennas, multiphysics modelling and additive manufacturing.

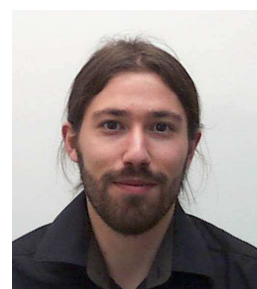

Vincent LE SAUX was born in Quimper, France, in 1984. He received the Engineering degree in mechanical engineering from ENSTA Bretagne, a French Graduate Engineering School, in 2007, and the $\mathrm{Ph} . \mathrm{D}$. degree in mechanical engineering from the Université Bretagne Occidentale, France, in 2010.

In 2007, he joined the Mechanics of Materials and Assemblies Team, Brest Laboratory of Mechanics and Systems, Brest, France, as a Research Assistant. In 2010, he joined the Heterogeneous Materials Behavior Team of the Brittany Laboratory of Engineering Materials, Lorient, France, as a Post-Doctoral Researcher. Since 2011, he has been an Assistant Professor at ENSTA Bretagne, conducting his research at IRDL Laboratory. His research interests mainly cover the analysis and prediction of the durability of polymers from experimental, modeling, and numerical points of view, with a specific focus on accurate thermal measurements using cooled infrared cameras.

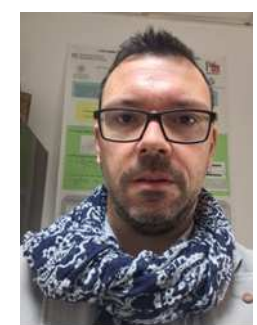

Stephan Marini (M'10) was born in Cagli, Italy, on January 3, 1976. He received the Laurea degree in electronics engineering from the University of Perugia, Italy, in 2001, and the Ph.D. degree in telecommunications from the Universidad Politécnica de Valencia, Spain, in 2005

In June 2001 he joined the "Departamento de Comunicaciones", Universidad Politécnica de Valencia, in the frame of the European Union project "Millimeter-wave and Microwave Components Design Framework for Ground and Space Multimedia Network" (MMCODEF). Since 2005 he has been a Lecturer with Departamento de Fsica, Ingeniera de Sistemas y Teoría de la Seal, Universidad de Alicante, Spain, where he became Associate Professor in 2012. In 2009 he obtained a fellowship from the Spanish Government for a short stay at the LEMA laboratory (cole Polytechnique Fédérale de Lausanne,Switzerland) as Visiting Scientific. His current research interests include numerical methods in computer-aided techniques for the analysis and design of microwave and millimeter passive components, and simulation of power effects (multipactor and corona) in passive waveguide systems.

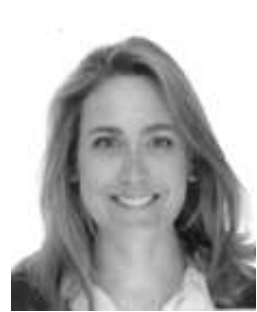

Marta S. Reglero received the Telecommunications Engineering degree from the Universitat Politècnica de Valencia (UPV), Valencia, Spain, in 2008. From 2006 to 2008 she was a Fellow Researcher with the Institute of Telecommunications and Multimedia Applications (iTEAM), Universitat Politècnica de València (UPV) and with the Department of Applied Physics Electromagnetism and the Institute of Materials Science (ICMUV), Universitat de València (UVEG). Since 2008, she is a Technical Researcher at iTEAM, UPV. And since 2010, she is a Laboratory Engineer at ESA-Val Space Consortium (VSC). Her current research interests are focused on the analysis of high power effects on microwave devices.

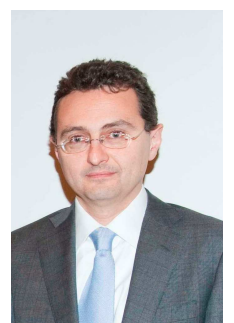

Vicente E. Boria (S'91-A'99-SM'02-F'18) was born in Valencia, Spain, on May 18, 1970. He received his "Ingeniero de Telecomunicación" degree (with first-class honors) and the "Doctor Ingeniero de Telecomunicación" degree from the Universidad Politécnica de Valencia, Valencia, Spain, in 1993 and 1997, respectively.

In 1993 he joined the "Departamento de Comunicaciones", Universidad Politcnica de Valencia, where he has been Full Professor since 2003. In 1995 and 1996, he was holding a Spanish Trainee position with the European Space Research and Technology Centre, European Space Agency (ESTEC-ESA), Noordwijk, The Netherlands, where he was involved in the area of EM analysis and design of passive waveguide devices. He has authored or co-authored 10 chapters in technical textbooks, 180 papers in refereed international technical journals, and over 200 papers in international conference proceedings. His current research interests are focused on the analysis and automated design of passive components, lefthanded and periodic structures, as well as on the simulation and measurement of power effects in passive waveguide systems.

Dr. Boria has been a member of the IEEE Microwave Theory and Techniques Society (IEEE MTT-S) and the IEEE Antennas and Propagation Society (IEEE AP-S) since 1992. He is also member of the European Microwave Association (EuMA), and has been the Chair of the 48th European Microwave Conference held in Madrid, Spain. He acts as a regular reviewer of the most relevant IEEE and IET technical journals on his areas of interest. He has been Associate Editor of IEEE Microwave and Wireless Components Letters (2013-2018) and IET Electronics Letters (2015-2018). Presently, he serves as Subject Editor (Microwaves) of IET Electronics Letters, and as Editorial Board member of International Journal of RF and Microwave Computer-Aided Engineering. He is also member of the Technical Committees of the IEEE-MTT International Microwave Symposium and of the European Microwave Conference. 
Cedric Quendo (IEEE SM15) received the Electrical Engineer degree and the $\mathrm{PhD}$ degree in Electrical Engineering from the University of Brest, France, in 1999 and 2001, respectively. Between 2001 and 2010, he gave courses and conducted research in several institutes. Since 2010, he is Professor with the Electronic Department, University of Brest, France. From 2012 to 2016, he was Vice-President of the University of Brest. Since 2017, he is the head of Microwaves Optoelectronics and Materials Group of the Lab-STICC Laboratory (more than 100 persons), France. His research activities principally concern the modelling and design of microwave devices for microwave and millimetre-wave applications. 